\title{
Concentração do zinco sérico em vacas leiteiras suplementadas com Saccharomyces cerevisiae, portadoras ou não de lesões podais
}

\author{
Serum zinc concentration of dairy cow supplemented with \\ Saccharomyces cerevisiae, with and without hoof lesions
}

\author{
Luiz Fernando Coelho da Cunha Filho ${ }^{1 *}$; Simone Biagio Chiacchio ${ }^{2}$; \\ Laurenil Gaste ${ }^{3}$; Roberto Calderon Gonçalves²; Luis Carlos Vianna ${ }^{4}$
}

\begin{abstract}
Resumo
Com o objetivo de determinar as concentrações de zinco no soro de bovinos com e sem lesões podais, suplementados ou não com Saccharomyces cerevisiae, como fonte de zinco orgânico, por 180 dias, foram selecionadas e examinadas 45 vacas holandesas pretas e brancas, escolhidas aleatoriamente em um rebanho de 189 vacas em lactação. Os animais foram distribuídos em três grupos, sendo grupo 1 (G1) composto por 20 vacas com lesões podais e suplementadas, grupo 2 (G2) 10 animais sem lesões e com suplementação, e grupo 3 (G3) 15 animais com lesões e sem suplementação. Amostras de soro foram coletadas no momento inicial (dia zero), 90 e 180 dias após início do experimento, sendo as concentrações determinadas por espectrofotometria de absorção atômica. Os resultados demonstram não haver um aumento sérico significativo de zinco entre os grupos, sendo que nos animais dentro do grupo 1 (G1) ocorreu um aumento $(\mathrm{P}<0,01)$ da concentração de zinco $(0,84$ para $1,16 \mu \mathrm{g} / \mathrm{mL})$. A suplementação oral de zinco orgânico não aumentou a concentração sérica de zinco, embora nos últimos 90 dias do experimento tenha ocorrido uma elevação do valor sérico de zinco nos grupos suplementados.
\end{abstract}

Palavras-chave: Bovinos, soro, Saccharomyces cerevisiae, zinco

\begin{abstract}
The present study was conducted to evaluate bovine serum zinc concentration in animals with and without hoof lesions, supplemented or not with Saccharomyces cerevisiae, an organic zinc source. The supplementation was carried out during 180 days. Forty-five Holstein cows were randomly chosen from a dairy herd of 189 lactating cows. The animals were distributed in three groups. In G1, 20 heifers with foot lesions were fed a diet supplemented with $S$. cerevisae. In G2, 10 heifers without hoof lesions were fed a diet with supplementation. In G3, 15 heifers with hoof lesions were fed a diet without supplementation. Serum samples were collected on day 0,90 and 180, after the beginning of the experiment. Serum zinc concentration was determined by Atomic Absorption Spectrophotometry. The results showed there not to be an increase significant serum of zinc among the groups, and in the animals inside of the group 1 (G1) it happened an increase $(P<0,01)$ of the concentration of zinc $(0,84$ for $1,16 \mu \mathrm{g} / \mathrm{mL}$ ). The oral supplementation of organic zinc didn't increase the concentration serum of zinc, although in the last 90 days of the experiment it has happened an elevation of the value serum of zinc in the groups supplemented.
\end{abstract}

Key words: Cattle, serum, Saccharomyces cerevisiae, zinc

${ }^{1}$ Departamento de Clínica Médica de Ruminantes, Universidade Norte do Paraná (UNOPAR), Arapongas, PR, Brasil. E-mail: luiz.cunha@unopar.br

2 Departamento de Clínica Veterinária, Universidade Estadual Paulista (UNESP), Botucatu, SP, Brasil.

3 Departamento de Clínicas Veterinárias, Universidade Estadual de Londrina (UEL), Londrina, PR, Brasil.

${ }^{4}$ Departamento de Clínica Veterinária, Universidade do Oeste Paulista (UNOESTE), Presidente Prudente, SP, Brasil.

* Autor para correspondência 


\section{Introdução}

O zinco é componente de mais de 300 metaloenzimas (MAFRA; COZZOLINO, 2004), e também está envolvido na estabilização de estruturas protéicas e ácidos nucléicos, na integridade de organelas subcelulares, assim como nos processos de transporte, função imunológica e expressão da informação genética, sendo necessário para a atividade das RNA polimerases, importantes na divisão celular (HENDLER, 1994; MAHAN; STUMP, 1998; MAFRA; COZZOLINO, 2004).

WrighteSpears (2004) confirmamqueruminantes suplementados com zinco orgânico têm maior concentração de zinco no plasma e nos tecidos, do que os alimentados com zinco inorgânico, quando o zinco é fornecido em concentrações relativamente altas.

Os níveis plasmáticos de zinco têm sido amplamente utilizados para o diagnóstico da deficiência de zinco, tanto em humanos como em animais (McDOWELL, 1999).

Bengoumi et al. (1998) demonstraram que houve um aumento do teor do zinco plasmático em bovinos, após a suplementação oral desse elemento, corroboram Piva et al. (1983), que observaram uma tendência de aumento do zinco plasmático após o uso oral de cultura de levedura em bovinos.

O objetivo dessa pesquisa foi avaliar o efeito da suplementação com Saccharomyces cerevisiae, como fonte de zinco, na dieta de vacas leiteiras em lactação por 180 dias, sobre a concentração sérica do elemento em animais portadores, ou não de lesões podais.

\section{Material e Métodos}

Foram utilizados animais pertencentes a um plantel de criação intensiva e produtora de leite do tipo B do município de Rio Bom - PR, constituídos por vacas da raça Holandês Preto e Branco, puro de origem, entre o $1^{\circ}$ e o $6^{\circ}$ mês de lactação, produzindo em média, $23 \mathrm{~kg} /$ leite/dia, com idade entre 2,5 e 6 anos e com peso médio corporal de $500 \mathrm{~kg}$. O rebanho foi mantido em regime de confinamento (free-stall), e no transcorrer do experimento, todos os animais receberam o mesmo manejo e a mesma alimentação, distribuída em duas porções iguais diárias, constituídas pelo total por $35 \mathrm{~kg}$ de silagem de milho, acrescidos de $8 \mathrm{~kg}$ de concentrado ${ }^{1}$ e mistura mineral ${ }^{2}$ e água ad libitum. A dieta básica seguindo as exigências nutricionais estabelecidas pelo NATIONAL RESEACH COUNCIL - NRC (2001).

Do plantel de 189 vacas em lactação, foram selecionados, dentre os animais que estavam no início da lactação, 35 animais com claudicação. Do grupo de animais que apresentaram claudicações, 20 foram aleatoriamente escolhidos, de modo a constituírem o grupo G1 e 15 animais foram reunidos no grupo G3. O grupo G2 foi constituído por 10 animais que não apresentavam claudicação e que possuíam poucas lesões nos cascos. Os grupos G1 e G2 foram suplementados uma vez ao dia com $5 \mathrm{~g}$ de levedura $S$. cerevisae ${ }^{3}$, como fonte de zinco, representando uma suplementação de $750 \mathrm{mg} / \mathrm{vaca} /$ dia do elemento zinco.

O período experimental foi dividido em duas etapas, uma de 25 dias, na qual os animais se adaptaram ao manejo (free-stall) e a alimentação (dieta basal), seguida de outra de 180 dias. Foram colhidas amostras de sangue nos dias zero, 90 e 180, mediante venopunção jugular, com agulhas $40 \times 12$, cujas amostras foram acondicionadas em tubos de $10 \mathrm{~mL}^{4}$ sem anticoagulante. Os frascos foram identificados e após 8 horas de descanso para obtenção de soro, o soro sobrenadante foi recuperado e acondicionado em tubos de $1,5 \mathrm{~mL}^{5}$, que foram depositados em caixa térmica, contendo gelo e transportados ao laboratório onde foram mantidos em freezer a $-20^{\circ} \mathrm{C}$, até o momento das respectivas nálises.

As amostras de soro congeladas passaram por digestão ácida (DEMERTZIS; MILLS, 1973) e após a completa destruição da matéria orgânica, 
foram acondicionadas em frascos de tampa rosca, previamente identificados, e enviadas ao Laboratório de Solos, UNESP - Campus de Botucatu - SP para a determinação do zinco em espectrofotômetro de absorção atômica ${ }^{7}$ (AAS).

O delineamento do experimento foi inteiramente aoacaso. Utilizou-sea análise devariância(ANOVA), seguida pelo teste de Tukey (MORRISON, 1990), para a comparação estatística das médias das concentrações de zinco no soro sanguíneo.

\section{Resultados e Discussão}

A Tabela 1 mostra os valores médios das concentrações de zinco sérico, nos diferentes grupos estudados.

A análise estatística dos resultados demonstra não haver diferenças significativas entre os grupos, portanto não ocorrendo incremento do zinco sérico, embora tenha ocorrido aumento do valor de zinco sérico dos grupos tratados (G1 e G2) nos últimos 90 dias do experimento, conforme representa a figura 1 .

Tabela 1. Valores médios obtidos para as concentrações de zinco nos soros $(\mu \mathrm{g} / \mathrm{mL})$ nos grupos suplementados $(\mathrm{G} 1 \mathrm{e}$ G2) e controle (G3) nos diferentes dias ( 0, 90 e 180).

\begin{tabular}{lllll}
\hline & \multicolumn{3}{c}{ Dias } \\
\cline { 2 - 5 } Grupos & 0 & 90 & 180 & P. \\
G1 & $0,84^{\mathrm{A}}$ & $0,87^{\mathrm{A}}$ & $1,16^{\mathrm{B}}$ & $<0,01$ \\
G2 & 0,86 & 0,78 & 1,03 & 0,20 \\
G3 & 0,90 & 0,87 & 0,92 & 0,74 \\
\hline P. & 0,49 & 0,63 & 0,10 & \\
\hline
\end{tabular}

Letras maiúsculas comparam médias dentro de cada grupo.

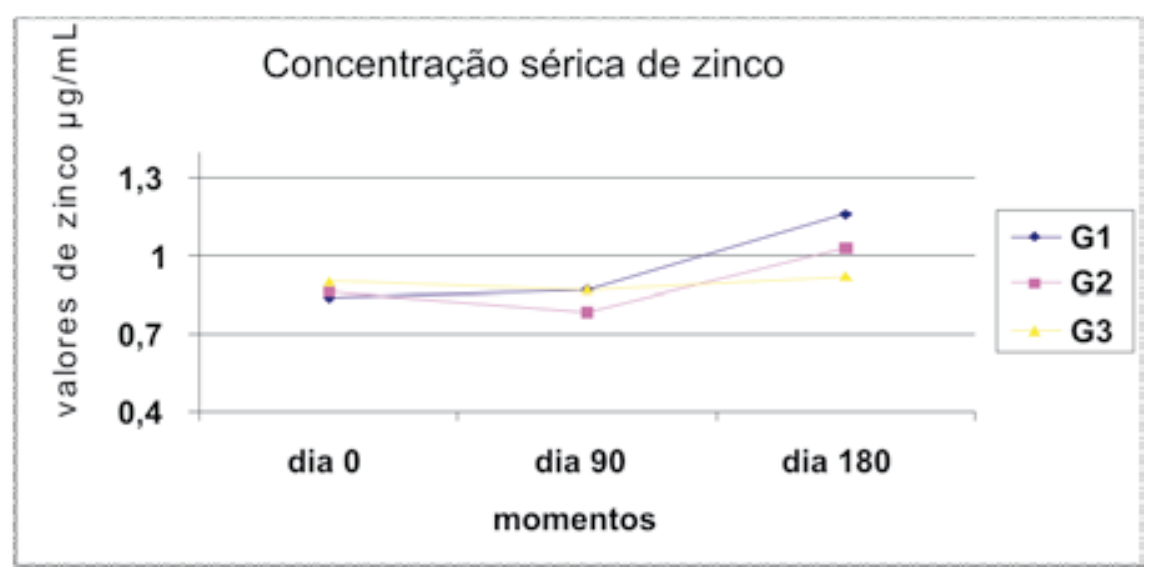

Figura 1. Valores médios obtidos para as concentrações séricas de zinco $(\mu \mathrm{g} / \mathrm{mL})$ nos animais dos diferentes grupos e nos diferentes momentos 
No grupo 1 (G1) ocorreu um aumento $(\mathrm{P}<0,01)$ da concentração de zinco, de $0,84 \pm 0,17 \mu \mathrm{g} / \mathrm{mL}$ para $1,16 \pm 0,26 \mu \mathrm{g} / \mathrm{mL}$, ao final dos 180 dias do experimento, conforme a tabela 1 .

Os valores de zinco séricos encontrados no trabalho, de $0,78 \pm 0,12 \mu \mathrm{g} / \mathrm{mL}$ a $1,16 \pm 0,26 \mu \mathrm{g} / \mathrm{mL}$, são compatíveis com os valores da literatura, os quais apresentam pequena variabilidade. Segundo Lamand (1987), Miller, Ramsey e Madsen (1988), Peixoto, Moura e Farb (1995), Bengoumi et al. (1998) e Rebhun (2000), os valores se situam entre $0,8 \mu \mathrm{g} / \mathrm{mL}$ a $1,2 \mu \mathrm{g} / \mathrm{mL}$ para os bovinos.

Entretanto os resultados obtidos divergem dos encontrados por Pardo (2001), que registrou valores de concentração de zinco nas amostras de plasma muito superiores, de 4,71 $\pm 1,25 \mu \mathrm{g} / \mathrm{mL}$ a 5,03 $\pm 0,76 \mu \mathrm{g} / \mathrm{mL}$, sendo que a metodologia utilizada para proceder a digestão ácida das amostras foi semelhante.

Colaboram com os achados do presente trabalho os resultados de Beeson, Perry e Zurcher (1977), Spears, Kegley e Roussel (1991), Bengoumi et al. (1998) e Lopez et al. (1999), os quais concluíram que a concentração sérica não foi influenciada pelo tratamento com zinco, portanto não houve um incremento da concentração de zinco no soro. Contudo, Miller et al . (1970), Wright e Spears (2004) e Popovic (2004) trabalhando com bovinos e Rojas et al. (1995) e Henry, Litell e Ammerman (1997) com ovinos, observaram que a concentração de zinco no plasma foi significativamente aumentada em animais alimentados com uma dieta com excesso de zinco, comparados com a dieta controle.

Dembinski e Wieckowski (1987) administraram $1,4 \mathrm{mg}$ de zinco/ $\mathrm{kg}$ de peso vivo diariamente, durante 70 dias, e os níveis séricos de zinco não aumentaram $(0,79$ e $0,87 \mu \mathrm{g} / \mathrm{mL}$, antes e depois da aplicação). Contudo, Egerton, Laing e Mulley (1985) relataram que a administração de até $82 \mathrm{mg}$ de zinco/ $\mathrm{kg}$ de peso vivo, diariamente em bovinos e ovinos, em dois períodos de cinco dias, promoveram um aumento de zinco no soro.
Wright e Spers (2004) relataram que as concentrações de zinco no plasma e nos tecidos colhidos foram similares no geral em bezerros suplementados com $20 \mathrm{mg} / \mathrm{kg}$ de zinco inorgânico $\left(\mathrm{ZnSO}_{4}\right)$ ou zinco orgânico (ZnProt). Colaboram Engle et al. (1997), ao afirmarem que as fontes de zinco (orgânico e inorgânico) não afetaram as concentrações do zinco plasmático em seu estudo. Entretanto, quando bezerros foram suplementados com $500 \mathrm{mg}$ de zinco/ kg, o zinco orgânico teve uma melhor absorção do que o zinco inorgânico, baseado, sobretudo nas maiores concentrações de zinco no plasma, fígado, duodeno e rins (WRIGHT; SPEARS, 2004).

Engle et al. (1997), registraram os valores de concentração de zinco sangüíneo entre $0,82 \pm 0,10$ $\mu \mathrm{g} / \mathrm{mL}$ e $1,07 \pm 0,38 \mu \mathrm{g} / \mathrm{mL}$, e concluíram que dietas deficientes de zinco não afetam as concentrações no plasma e fígado de bezerros.

A concentração sérica de zinco tem sérias limitações para o estabelecimento do estatus de zinco nos animais (KEEN; GRAHAM, 1989; SWENSON et al., 1996; HENRY; LITELL; AMMERMAN, 1997; OLSON et al., 1999). No entanto, alguns autores têm citado concentrações de zinco sérico ou plasmático nos seus estudos de eficácia da suplementação de zinco no tratamento do "foot rot", e têm concluído que a eficácia pode estar ligada à pré-existência de uma deficiência de zinco nos animais afetados, baseado no baixo nível sérico ou plasmático (LOPEZ et al., 1999). Os resultados obtidos na pesquisa demonstram não haver deficiência de zinco nas vacas estudadas, mesmo os animais do G3 (controle) apresentaram valores séricos dentro do padrão de normalidade.

Alguns autores relataram que os processos infecciosos diminuem a concentração do zinco sérico (SPEARS; KEGLEY; ROUSSEL, 1991; CHIRASE et al., 1994), provavelmente por um aporte maior do elemento para os tecidos lesados, além de sua utilização na resposta imune. O zinco é fundamental na síntese de queratina para a produção e manutenção 
da integridade dos cascos (NICOLETTI, 2004), consequentemente as lesões podais demandam um consumo expressivo do elemento zinco na reparação cicatricial. Os resultados obtidos na pesquisa demonstraram não haver diferenças significativas da concentração sérica de zinco entre as vacas com e sem claudicação (G1/G3 e G2 respectivamente), portanto as afecções podais não influenciaram a concentração plasmática de zinco.

Em ruminantes, níveis séricos normais de zinco estão entre 0,72 e $1,17 \mu \mathrm{g} / \mathrm{mL}$, e animais com níveis abaixo de $0,68 \mu \mathrm{g} / \mathrm{mL}$ são considerados deficientes (LAMAND, 1987). McDowell, Velasquez-Pereira e Valle (1997) corroboram ao afirmarem que para se determinar a deficiência em grandes populações de ruminantes, deve-se considerar uma combinação de concentração baixa de zinco no plasma $(0,6$ a $0,8 \mu \mathrm{g} / \mathrm{mL}$ ) e na forragem ( $40 \mathrm{mg} / \mathrm{Kg}$ de MS), este procedimento seria um bom indicador do estado do zinco.

\section{Conclusão}

A suplementação oral de $750 \mathrm{mg}$ de zinco orgânico (S. cerevisiae) para vacas em lactação por 180 dias não aumentou a concentração sérica de zinco, embora tenha ocorrido biologicamente aumento do valor de zinco sérico dos grupos tratados (G1 e G2) nos últimos 90 dias do experimento;

\section{Agradecimentos}

A secção de Pós-graduação da FMVZ da UNESP de Botucatu-SP e da UNOPAR-PR.

A Alltech do Brasil $^{\circledR}$ pelo fornecimento da levedura de zinco.

\section{Fonte de aquisição}

${ }^{1}$ Colari $20 \% \AA$

${ }^{2}$ Fosbov 20 Tortuga ${ }^{\circledR}$
${ }^{3}$ Bioplex Zinco Allthec ${ }^{\circledR}$

${ }^{4}$ Vacutainer-BD ${ }^{\circledR}$

${ }^{5}$ Eppendorf®

${ }^{6}$ Frascolex

${ }^{7}$ Varian - modelo AA- 800

\section{Referências}

BEESON, W. M.; PERRY, T. W.; ZURCHER, T. D. Effect of supplemental zinc on growth and on hair and blod serum levels of beel cattle. Journal of Animal Science, Champaign, v. 45, n. 1, p. 160-165, 1977.

BENGOUMI, M.; ESSAMADI, K.; CHARCORNAC, J. P.; TRESSOL, J. C.; FAYE, B. Comparative relationship between copper-zinc plasma concentrations and superoxide dismutase activity in camels and cows. Veterinary Research, Les Ulis, v. 29, n. 6., p. 557-565, 1998.

CHIRASE, N. K.; HUTCHESON, D. P.; THOMPSON, G. B.; SPEARS, J. W. Recovery rate and plasma zinc and copper concentrations of steer calves fed organic and inorganic zinc and manganese sources with or without injectable copper and challenged with infectious bovine rhinotracheitis virus. Journal of Animal Science, Champaign, v. 72, n. 1, p. 212-219, 1994.

DEMBINSKI, P. N.; WIECKOWSKI, W. Application of zinc in cases in pododermatitis in cattle. Bulletin Veterinary Institute in Pulawy, Pulawy, v. 30-31, p. 104112, 1987.

DEMERTZIS, P. N.; MILLS, C. F. Oral zinc therapy in the control of infectious pododermatitis in young bulls. The Veterinary Record, London, v. 93, n. 8, p. 219-222, Aug. 1973.

EGERTON, J. R.; LAING, E. A.; MULLEY, R. C. Failure of oral zinc therapy to alleviate Bacteroides nodosus infections in cattle and sheep. Australian Veterinary Journal, Brunswick, v. 62, n. 3, p. 85-88, 1985.

ENGLE, T. E.; NOCKELS, C. F.; KIMBERLING, C. V.; WEABER, D. L.; JOHNSON, A. B. Zinc repletion with organic or inorganic forms of zinc and protein turnover in marginally zinc- deficient calves. Journal of Animal Science, Champaign, v. 75, n. 11, p. 3074-3081, 1997.

HENDLER, S. S. Enciclopédia de vitaminas e minerais. Rio de Janeiro: Campus, 1994.

HENRY, P. R.; LITELL, R. C.; AMMERMAN, C. B. Effect of high dietary zinc concentration and length on 
zinc feeding on feed intake and tissue zinc concentration in sheep. Animal Feed Science and Technology, Amsterdam, v. 66, n. 1, p. 237-245, May 1997.

KEEN, C. L.; GRAHAM, T. W. Trace elements. In: KANEKO, J. J. (Ed.) Clinical biochemistry of domestic animals. 4.ed. San Diego: Academic Press, 1989. p. 753795.

LAMAND, M. Place du laboratoire dans le diagnostic des carences en oligoélements chez les ruminants (Importance of analytical laboratory intrace element deficiency diagnosis). Revue de Medecine Veterinaire, Toulouse, v. 163, n. 11, p. 1071-1082, 1987.

LOPEZ, J. R.; MONTANA, J. R. G.; DÍEZ, A. J. A.; MONTANA, F. P. Failure of oral zinc supplementation to control ovine foot rot. Small Ruminat Research, Amsterdam, v. 31, n. 3, p. 273-276, 1999.

MAFRA, D.; COZZOLINO, S. M. F. Importância do zinco na nutrição humana. Revista de Nutrição, Campinas, v. 17, n. 1, p. 79-87, 2004.

MAHAN, L. K.; STUMMP, S. E. KRAUSE: alimentos, nutrição e dietoterapia. 9.ed. São Paulo: Roca, 1998.

McDOWELL, L. R. Minerais para ruminantes sob pastejo em regiões tropicais, enfatizando o Brasil. 3.ed. Bannochburn: IMC-Agrico Food Ingredients, 1999.

McDOWELL, L. R.; VELASQUEZ-PEREIRA, J.; VALLE, G. Minerales para rumiantes en pastoreo en regiones tropicales. 3.ed. Bannochburn: IMC-Agrico Food Ingredients, 1997.

MILLER, J. K.; RAMSEY, N.; MADSEN, F. C. The trace elements. In: CHURCH, D. C. (Ed.) The ruminant animal digestive physiology and nutrition. Englewood: Pretice Hall, 1988. p. 342-400.

MILLER, W. J.; BLACKMON, D. M.; GENTRY, R. P.; PATE, F. M. Effects of high but nontoxic levels on zinc in practical diets on ${ }^{65} \mathrm{Zn}$ and zinc metabolism in holstein calves. Journal Nutrition, Philadelphia, v. 100, n. 8, p. 893-902, 1970.

MORRISON, D. F. Multivariate statistical methods. São Paulo: McGraw Hill, 1990.

NATIONAL RESEARCH COUNCIL- NRC. Nutrient requirements of dairy cattle. 7.ed. Washington: National Academic Science, 2001.

NICOLETTI, J. L. M. Manual de podologia bovina. Barueri: Manole, 2004.
OLSON, P. A.; BRINK, D. R.; HICKOK, D. T.; CARLSON, M. P.; SCHNEIDER, N. R.; DEUTSCHER, G. H.; ADAMS, D. C.; COLBURN, D. J.; JOHNSON, A. B. Effects of supplementation of organic and inorganic combinations of copper, cobalt, manganese, and zinc above nutrient requirement levels on postpartum twoyear-old cows. Journal of Animal Science, Champaign, v. 77, n. 3, p. 522-532, 1999.

PARDO, P. E. Determinação do zinco plasmático e da sola do casco de bovinos leiteiros com ou sem lesões podais, suplementados ou não com levedura seca de cana de açúcar. 2001. Tese. (Doutorado em Medicina Veterinária) - Universidade Estadual Paulista, Botucatu.

PEIXOTO, A. M.; MOURA, J. C.; FARB, V. P. Nutrição de bovinos: conceitos básicos $\mathrm{e}$ aplicados. 5.ed. Piracicaba: FEALQ, 1995.

PIVA, G.; BELLADONNA, S.; FUSCONI, G.; SICBALDI, F. Effects of yeast on dairy cow performance, ruminal fermentation, blood components, and milk manufacturing properties. Journal of Dairy Science, Champaign, v. 76, n. 9, p. 2717-2722, 1983.

POPOVIC, Z. Performance and udder health status of dairy cows influenced by organically bound zinc and chromium. 2004. Thesis. (Ph.D) - Faculty of Veterinary Medicine, University of Belgrade, Belgrade.

REBHUN, W. C. Doenças do gado leiteiro. São Paulo: Roca, 2000.

ROJAS, L. X.; McDOWELL, L. R.; COUSINS, R. J.; MARTIN, F. G.; WILKISON, N. S.; JOHNSON, A. B.; VELASQUEZ, J. B. Relative bioavailability of two organic and two inorganic zinc sources fed to sheep. Journal of Animal Science, Champaign, v. 73, n. 4, p. 1202-1207, 1995.

SPEARS, J. W.; KEGLEY, E. B.; ROUSSEL, J. D. Effects of zinc methionine and zinc oxide on performance, blood characteristics, and antibody titer response to viral vaccination in stressed feeder calves. Journal of the American Veterinary Medical Association, Schaumburg, v. 199, n. 12, p. 1731-1733, 1991.

SWENSON, C. K.; ANSOTEGUI, R. P.; SWENSSON, E. J.; PATERSON, J. A.; JOHNSON, A. B. Influence of mineral supplementation on blood serum and liver mineral concentration in first-calf beef heifers and their calves. Journal of Animal Science, Champaign, v. 74, n. 1, p. 616-619, 1996.

WRIGHT, C. L.; SPEARS, J. W. Effect of zinc source and dietary level an zinc metabolism in holstein calves. Journal of Dairy Science, Champaign, v. 87, n. 4, p. 1085-1091, 2004. 